\title{
Immunopolarization of $\mathrm{CD4}^{+}$and $\mathrm{CD8}^{+} \mathrm{T}^{\text {Cells to }}$ Type-1-Like is Associated with Melanocyte Loss in Human Vitiligo
}

\author{
Anna Wańkowicz-Kalińska, René M. J. G. J. van den Wijngaard, Bert J. Tigges, \\ Wiete Westerhof, Graham S. Ogg, Vincenzo Cerundolo, Walter J. Storkus, and \\ Pranab K. Das
}

Departments of Pathology (AWK, RMJGJvdW, BJT, PKD) and Dermatology (WW, PKD), Academic Medical Center/University of Amsterdam, Dutch Institute for Pigmentary Disorders (SNIP) (WW), Amsterdam, The Netherlands; MRC Human Immunology Unit (GSO, VC), Institute of Molecular Medicine, Oxford, United Kingdom; and University of Pittsburgh Medical Center (AWK, WJS), Pittsburgh, Pennsylvania

\begin{abstract}
SUMMARY: Vitiligo is an autoimmune condition characterized by loss of epidermal melanocytes. High frequencies of melanocyte-reactive cytotoxic T cells in the peripheral blood of vitiligo patients and the observed correlation between perilesional T-cell infiltration and melanocyte loss in situ suggest the important role of cellular autoimmunity in the pathogenesis of this disease. We isolated T cells from both perilesional and nonlesional skin biopsies obtained from five vitiligo patients, then cloned and analyzed their profile of cytokine production after short-term, nonspecific expansion in vitro. Perilesional T-cell clones (TCC) derived from patients with vitiligo exhibited a predominant Type-1-like cytokine secretion profile, whereas the degree of Type-1 polarization in uninvolved skin-derived TCC correlated with the process of microscopically observed melanocyte destruction in situ. Detailed analysis of broad spectrum of cytokines produced by perilesional- and nonlesional-derived CD4 ${ }^{+}$and CD8 ${ }^{+}$TCC confirmed polarization toward Type-1-like in both CD4 and CD8 compartments, which paralleled depigmentation process observed locally in the skin. Furthermore, $\mathrm{CD}^{+}$TCC derived from two patients also were analyzed for reactivity against autologous melanocytes. The antimelanocyte cytotoxic reactivity was observed among CD8 ${ }^{+} \mathrm{TCC}$ isolated from perilesional biopsies of two patients with vitiligo. Finally, in two of five patients, tetramer analysis revealed presence of high frequencies of Mart-1-specific CD8 T cells in T-cell lines derived from perilesional skin. Altogether our data support the role of cellular mechanisms playing a significant part in the destruction of melanocytes in human autoimmune vitiligo. (Lab Invest 2003, 83:683695).
\end{abstract}

$V$ itiligo is a skin disorder characterized by depigmented lesions caused by the loss of melanocytes, which are highly specialized cells responsible for skin pigmentation (Le Poole et al, 1993b). The process of depigmentation is possibly mediated by host autoimmunity to pigment cells. Melanocytespecific autoantibodies (Harning et al, 1991; Kemp et al, 2002) and cytotoxic T cells (Ogg et al, 1998; Palermo et al, 2001) have been found in the peripheral blood of vitiligo patients, with cellular immune responses most significantly correlating with the devel-

\section{DOI: 10.1097/01.LAB.0000069521.42488.1B}

Received September 26, 2002.

This work was performed under the research programs of ODP-9 and ODP-10 of Jan van Loghem Immunology Institute, Academic Medical Center, University of Amsterdam. PKD acknowledges support from Dutch Leprosy Relief Association (grant no. 702.02.42), Q.M. Gastman Wichers Foundation, NL, and the Experimental Dermato-Immuno-pathology Funds. $A W-K$ and $R M J G J v d W$ are recipients of financial support from Stiefel Laboratories (United Kingdom).

Address reprint requests to: Dr. P.K. Das, Department of Pathology (L2258), Academic Medical Center, Meibergdreef 9, 1105 AZ Amsterdam, The Netherlands.E-mail:p.k.das@amc.uva.nl opment of vitiligo. Indeed, patient peripheral-bloodderived CTLs specific for the melanocyte differentiation antigen Mart-1/Melan A have been reported to express the skin-homing receptor, cutaneous lymphocyte-associated antigen (CLA), and kill HLA-matched melanoma cells in vitro and their frequency in the peripheral blood correlated with disease severity. In addition, it could be demonstrated that the presence of macrophages and $T$ cells, particularly $\mathrm{CLA}^{+}$cytotoxic CD8 ${ }^{+} \mathrm{T}$ cells, in the perilesional $(\mathrm{PL})$ skin, parallels the disappearance of melanocytes (Le Poole et al, 1996; van den Wijngaard et al, 2000). Interestingly, widespread depigmentation and accumulation of Mart-1-specific $T$ cells within depigmented lesions was reported to occur after therapeutical passive transfer of these cells into a melanoma patient (Yee et al, 2000). However, the pathophysiology of spontaneously developing vitiligo remains unclear, and $\mathrm{T}$ cells infiltrating the skin remain poorly defined. In literature, clinical and experimental findings clearly show that cytokines play a major role in the development of autoimmunity at several levels. The relative contribution of Type- 1 or Type- $2 \mathrm{~T}$ cells with distinct cytokine profile is associated with the devel- 
opment of distinct autoimmune responses and can influence whether the particular disease process is cell- or antibody-mediated (Liblau et al, 1995). Type-1-like T cells produce mainly IFN- $\gamma$ and TNF- $\alpha$ and support cellular responses, being involved in organ-specific autoimmunity and immune responses to intracellular pathogens. On the other hand, Type-2-like $\mathrm{T}$ cells, producing mainly IL-4, IL-5, and IL-13, play a role in antibody-mediated responses (Mosmann and Sad, 1996).

It remains unclear whether cellular or humoral responses are involved in mediating melanocyte death in human vitiligo. We, therefore, have characterized T-cell lines (TCL) and T-cell clones (TCC) isolated directly from the site of depigmentation, as well as from macroscopically uninvolved skin (as an internal control) derived from patients with vitiligo. We demonstrate that polarization of cytokine profiles of TCL and TCC toward a Type-1-like pattern (with high production of IFN- $\gamma$ and TNF- $\alpha$, but not IL-4, IL5, IL-6, nor IL-10) is associated with depigmentation of PL skin and in microscopic depigmented foci found in normally pigmented skin of these patients, whereas Type- 0 or Type- 2 pattern is usually predominant without such foci. Furthermore, TCL generated from PL sites of two patients contained high frequencies of Mart-1-specific CD8 T cells.

\section{Results}

\section{Clinical Aspects of the Patients Studied}

Five patients were diagnosed with generalized vitiligo, characterized by the appearance of depigmentation regions in a bilateral, symmetrical fashion. Clinical diagnosis of disease activity in each patient was based on three criteria: appearance of new lesions within the preceding 3 months, spreading of existing lesions within last 3 months, or the presence of the Köbner phenomenon (depigmentation induced by trauma). Based on these criteria, four of five patients were diagnosed with active vitiligo, and Patient 5 displayed stable disease (Table 1).

\section{In Situ Analysis of T-Cell Infiltrates}

Immunohistochemical analysis (Fig. 1) of skin biopsies derived from PL skin in all five patients revealed a clearly delineated lesional area devoid of melanocytes, as evidenced by the lack of staining with NKI-beteb antibody specific for the melanosomal gp-100 antigen. Lesional staining with anti-CD3 mAb revealed the characteristic presence of T-cell infiltrates, located predominantly in the dermoepidermal junction of the skin sections, in the close proximity of melanocytes (Fig. 1, A, C, E, and G). Double staining obtained with anti-CD3 and anti-CD8 monoclonal antibodies (not shown) indicated that in all cases, the majority of PL skin T cells belonged to the $\mathrm{CD}^{+} \mathrm{CD}^{+}$subset (Table 2 ). Moreover, T cells present in the PL area of the biopsies strongly expressed HLA-DR molecules and perforin and granzyme B (not shown), consistent with an activated, effector CTL phenotype as described previously (van den Wijngaard et al, 2000). A different pattern of T-cell infiltrates was observed for Patient 5 (Fig. 1I). Although the lesional area was well demarcated, the T-cell infiltrate appeared to be "in recess," localized to the dermis only, and not clearly interacting with melanocytes.

Surprisingly, biopsies taken from macroscopically uninvolved skin from three of five patients showed T-cell infiltration into the epidermis paralleled by localized loss of melanocytes. This process, which we refer to as "microdepigmentation," was observed in Patients 2, 3, and 5 (Fig. 1, D, F, and J). It was most pronounced in the nonlesional (NL) skin of Patient 3, as evidenced by double staining with anti-CD3 and $\mathrm{NKI}$-beteb mAbs (Fig. 1F). Infiltrates consisted of equal proportions of $\mathrm{CD}^{+}$and $\mathrm{CD}^{+}{ }^{+} \mathrm{T}$ cells that appeared to be activated in situ based on their expression of HLA-DR. In the case of Patients 1 and 4, noninvolved skin was free of "microdepigmentation," and T-cell infiltrates (predominantly consisting of $\mathrm{CD}^{+} \mathrm{T}$ cells) were localized to the deep reticular dermis (Fig. 1, B and $\mathrm{H}$ ).

Similar immunostaining of skin biopsies derived from normal, healthy individuals showed sporadic presence of both CD4- and CD8-positive T cells around epidermis without any sign of melanocyte degeneration. Staining of skin biopsies from patients with other inflammatory dermatoses showed abundant presence of $\mathrm{T}$ cells in proximity of melanocytes, however, without any sign of clustering around melanocytes nor their destruction (Le Poole et al, 1996; van den Wijngaard et al, 2000).

\section{Phenotype of NL and PL Skin-Derived T-Cell Lines and Clones}

TCL extravasated from the skin biopsies were expanded by mitogenic stimulation in vitro. We success-

Table 1. Clinical Aspects of Patients Included in the Study

\begin{tabular}{|c|c|c|c|c|c|c|c|}
\hline Patient & $\begin{array}{l}\text { Age } \\
\text { (yr) }\end{array}$ & Sex & $\begin{array}{l}\text { Duration } \\
\text { of vitiligo }\end{array}$ & $\begin{array}{l}\text { Clinical } \\
\text { diagnosis } \\
\text { of vitiligo }\end{array}$ & $\begin{array}{c}\text { Clinical status } \\
\text { at the time of } \\
\text { biopsy }\end{array}$ & Therapy & Follow-up \\
\hline 1 & 42 & female & $25 \mathrm{yr}$ & generalized & active & PUVA & stable \\
\hline 2 & 64 & female & $14 \mathrm{yr}$ & generalized & active & NA & $N A$ \\
\hline 3 & 32 & female & $20 \mathrm{yr}$ & generalized & active & UVB & active \\
\hline 4 & 45 & female & 7 months & generalized & active & TS, UVB & stable \\
\hline 5 & 59 & male & $25 \mathrm{yr}$ & generalized & stable & no therapy & stable \\
\hline
\end{tabular}

TS, topical steroids; UVA, UVB, treatment with ultraviolet light; PUVA, combined treatment with ultraviolet light and light-sensitizing factor; NA, data not available. 


\section{PL skin}
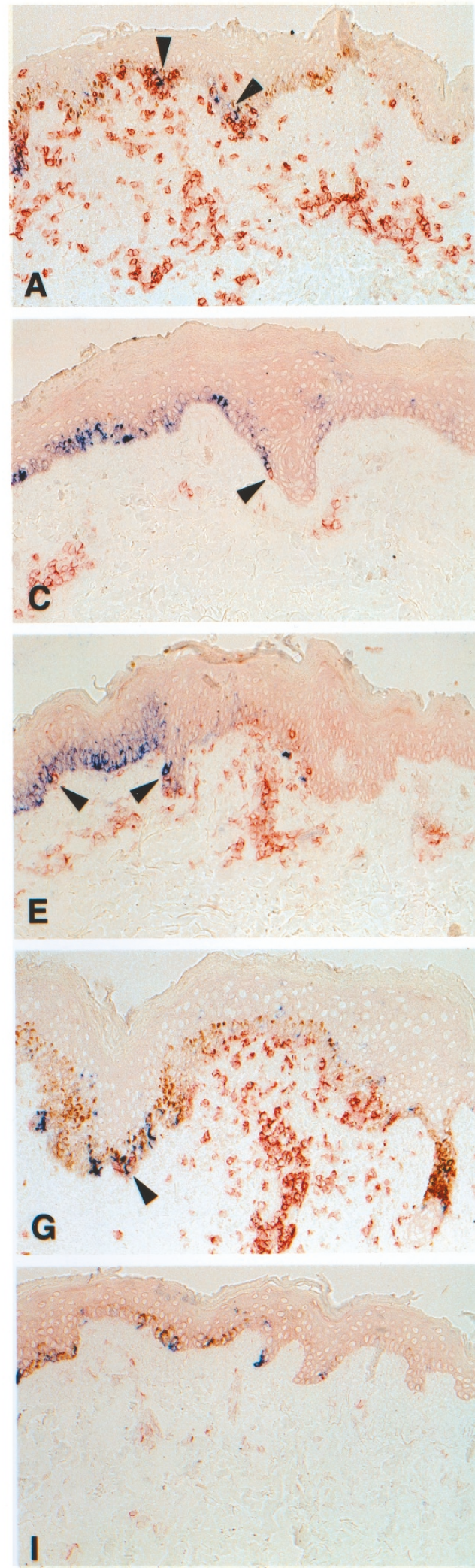

NL skin
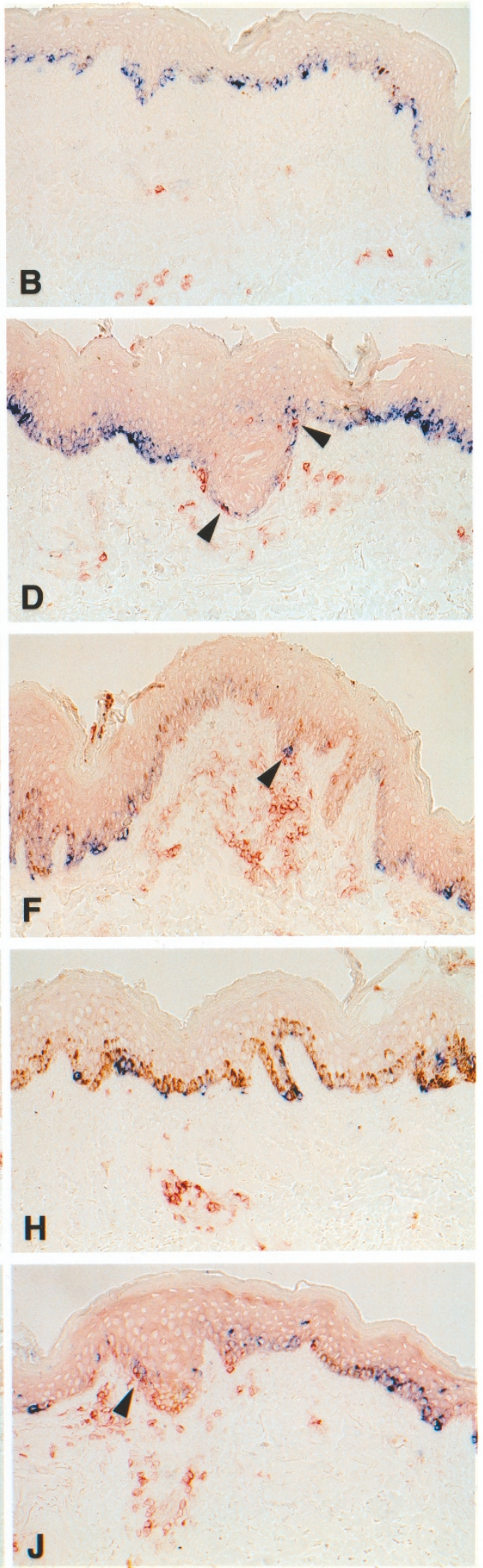

\section{Figure 1.}

Perilesional $(\mathrm{PL})$ and nonlesional $(\mathrm{NL})$ skin biopsies of active $(\mathrm{A}-\mathrm{H})$ and stable (I and J) vitiligo patients. A and $\mathrm{B}, \mathrm{Patient} 1$; C and $\mathrm{D}$, Patient 2; E and $\mathrm{F}$, Patient 3 ; $\mathrm{G}$ and $\mathrm{H}$, Patient 4; I and J, Patient 5. NKI/beteb (blue)/CD3 (red) double staining shows T cells apposed to melanocytes. Possible interaction areas (arrows). 
fully generated TCL from the PL and uninvolved skin biopsies of Patients 1 to 5 .

In four of five patients, the phenotype of the TCL reflected the similar percentage distribution to that of the in situ phenotype of T-cell infiltrates (Table 2). The only exception, PL TCL from Patient 4, displayed higher percentage of $\mathrm{CD}^{+} \mathrm{T}$ cells in vitro $(95 \%)$ than was observed in situ (48\%). Whereas NL TCL consisted of equal percentages of $\mathrm{CD} 4^{+}$and $\mathrm{CD} 8^{+} \mathrm{T}$ cells (Patients 2 and 3 ) or predominantly of $\mathrm{CD}^{+}{ }^{+} \mathrm{T}$ cells (Patients 1 and 4), PL biopsies yielded TCL containing high percentages of $\mathrm{CD}^{+}$cells in all cases.

TCL derived from the PL skin of all patients were cloned successfully, with both $\mathrm{CD}^{+}$and $\mathrm{CD}^{+}$ clones generated with varying cloning efficiencies (Table 2). By cloning procedure it also can be demonstrated that percentages of CD8- and CD4-positive TCC in PL skin differed considerably from those of NL site. In the former case, predominance of CD8positive TCC was more conspicuous. We generated from Patient 1: 17 CD4 TCC from NL skin, 8 CD4 and 34 CD8 TCC from PL skin; Patient 2: 48 CD4 TCC from NL skin, 32 CD4 and 12 CD8 TCC from PL skin; Patient 3: 14 CD4 TCC and 13 CD8 TCC from NL skin, 2 CD4 TCC and 13 CD8 TCC from PL skin; Patient 4: 1 CD4 and 55 CD8 TCC from PL skin (T-cell cloning from NL TCL was not successful); Patient 5: 8 CD4 TCC and 30 CD8 TCC from NL skin, and 19 CD4 and 19 CD8 TCC from PL skin.

\section{IFN- $\gamma /$ IL-4 Production by Vitiligo T Cells}

To characterize the cytokine profiles of TCL and TCC, we analyzed the production of IFN- $\gamma$ and IL- 4 by these T cells after 24-hour stimulation with OKT3 and PMA. Clear-cut differences in the IFN- $\gamma / \mathrm{IL}-4$ production ratio between $\mathrm{PL}$ and $\mathrm{NL}$ cells were detectable already in TCL (data not shown). We observed a 6 - to 30 -fold higher IFN- $\gamma / \mathrm{IL}-4$ ratio in the TCL from PL skin compared with that from NL skin, with the highest ratio reaching 226 for the perilesional TCL of Patient 3. Only in the case of Patient 5, both NL and PL TCL produced IFN- $\gamma$ and IL-4 in a similar ratio.

Analysis of IFN- $\gamma$ and IL-4 production by the individual $\mathrm{CD} 4^{+}$and $\mathrm{CD} 8^{+} \mathrm{TCC}$ also was performed. As shown in Figures 2 and 3, PL TCC (both $\mathrm{CD} 4^{+}$and $\mathrm{CD}^{+}$) produced predominantly IFN- $\gamma$, and most displayed IFN- $\gamma / \mathrm{IL}-4$ production ratios in excess of 20 . These clones were considered Type-1-like (Verhagen et al, 1997). Patient 5 was the exception, with most of the $\mathrm{CD}^{+}$and $\mathrm{CD}^{+}$clones classified as Type-0-like (IFN- $\gamma / \mathrm{IL}-4$ ratios between 0.4 and 20 ) and Type-2-like (IFN- $\gamma / \mathrm{IL}-4$ ratios lower than 0.4 ). The majority of the NL skin TCC were found to belong to the Type-0-like or Type-2-like subsets. Only in the case of Patient 3, whose NL skin displayed the most pronounced "microdepigmentation," the majority of both $\mathrm{CD}^{+}$and $\mathrm{CD}^{+}$TCC were Type-1-like. Interestingly, this patient showed appearance of new depigmented lesions during the course of this study.

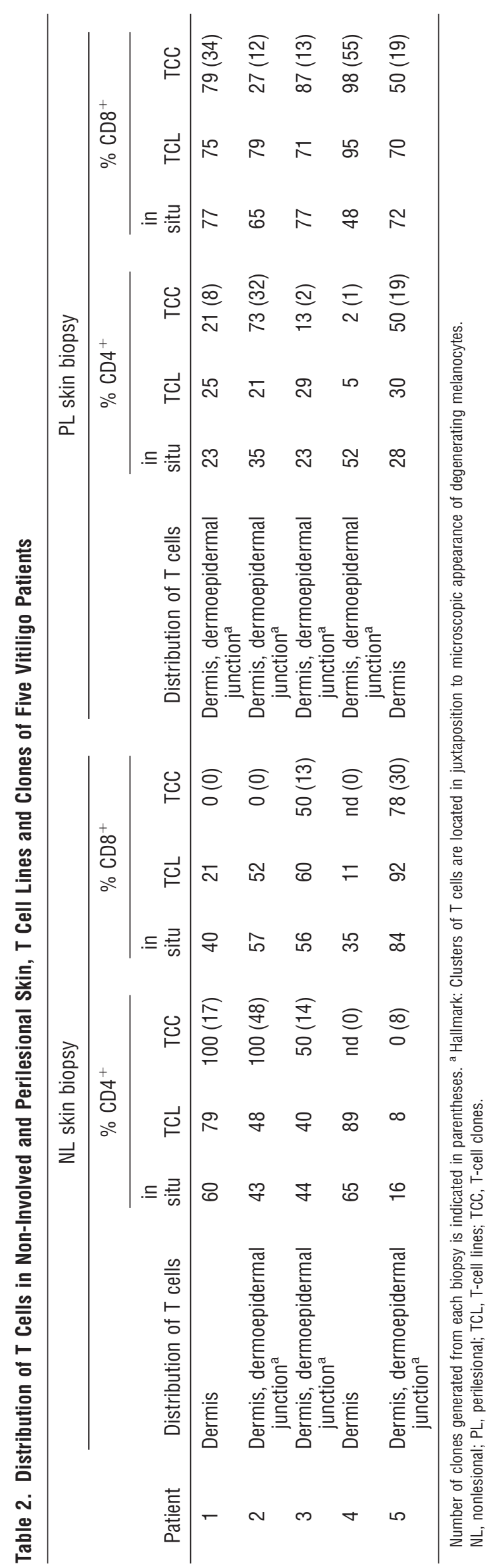



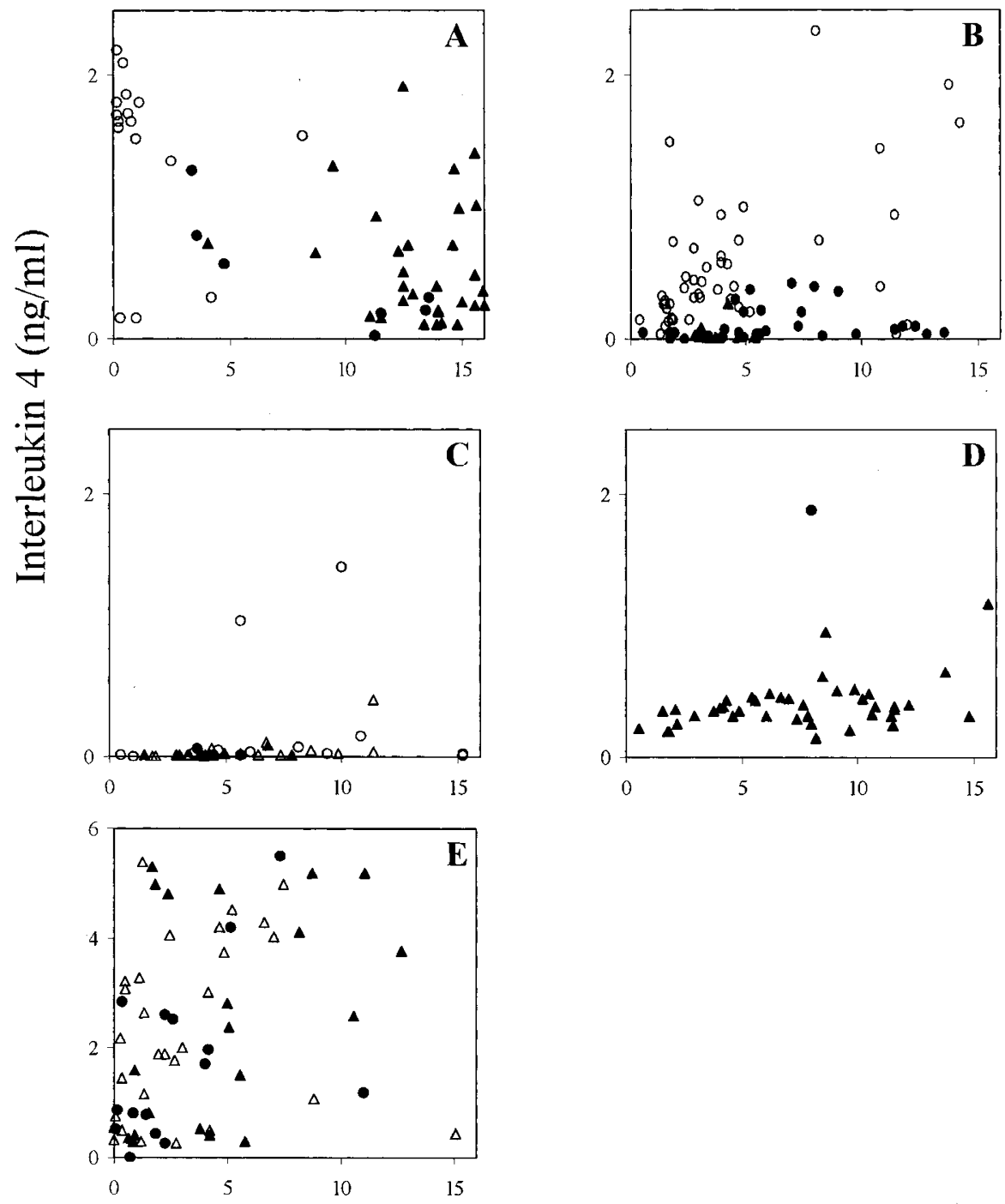

Interferon $\gamma(\mathrm{ng} / \mathrm{ml})$

Figure 2.

Production of IFN- $\gamma(\mathrm{ng} / \mathrm{ml})$ and IL-4 (ng/ml) by vitiligo T-cell clones (TCC) after 24-hour stimulation with OKT3 and PMA (see "Material and Methods"). A, Patient 1; B, Patient 2; C, Patient 3; D, Patient 4; E, Patient 5. NL CD4 ${ }^{+}$TCC (open circle); NL CD8 ${ }^{+}$TCC (open triangle); PL CD4 ${ }^{+}$TCC (closed circle); PL CD8 ${ }^{+}$TCC (closed triang/e). D, No NL TCC were generated for Patient 4.

\section{Further Characterization of Cytokine Profile of Vitiligo-Skin-Derived TCC}

To further characterize T cells infiltrating depigmented areas and compare their cytokine profiles to that present in the normal skin areas, we determined the production of IL-5, IL-6, IL-10, IL-13, and TNF- $\alpha$ in the same supernatants that were used for detection of IFN- $\gamma$ and IL-4. Table 3 shows mean cytokine production of a total of 249 TCC generated from both NL and PL skin of four active vitiligo patients and a total of 76 TCC generated from one patient with stable vitiligo. As shown, IL-5 and IL-13 production generally followed the polarization pattern of IL-4. The highest amounts of IL-5 and IL-13 were produced by Type-2 NL TCC generated from uninvolved skin of active vitiligo pa- tient that did not show any sings of microdepigmentation (15.3 \pm 32.5 and $15 \pm 13 \mathrm{ng} / \mathrm{ml}$, respectively). Considerable levels of IL- 5 and IL- 13 were produced by Type-2 clones derived from NL and PL skin of a stable vitiligo patient and by Type-0 NL and PL TCC derived from all patients. However, there was hardly any production of IL-5 and low but still detectable production of IL-13 by Type-1 TCC generated from all patients. IL-6 and IL-10 were not detected in significant amounts by any of the T-cell populations studied. TNF- $\alpha$ was produced by all of the clones tested in this study. Interestingly, the production of TNF- $\alpha$ by Type-1 and Type-0 PL TCC from four active patients seems to be prominent compared with those of a one stable patient, although the differences observed are 
Perilesional skin TCC
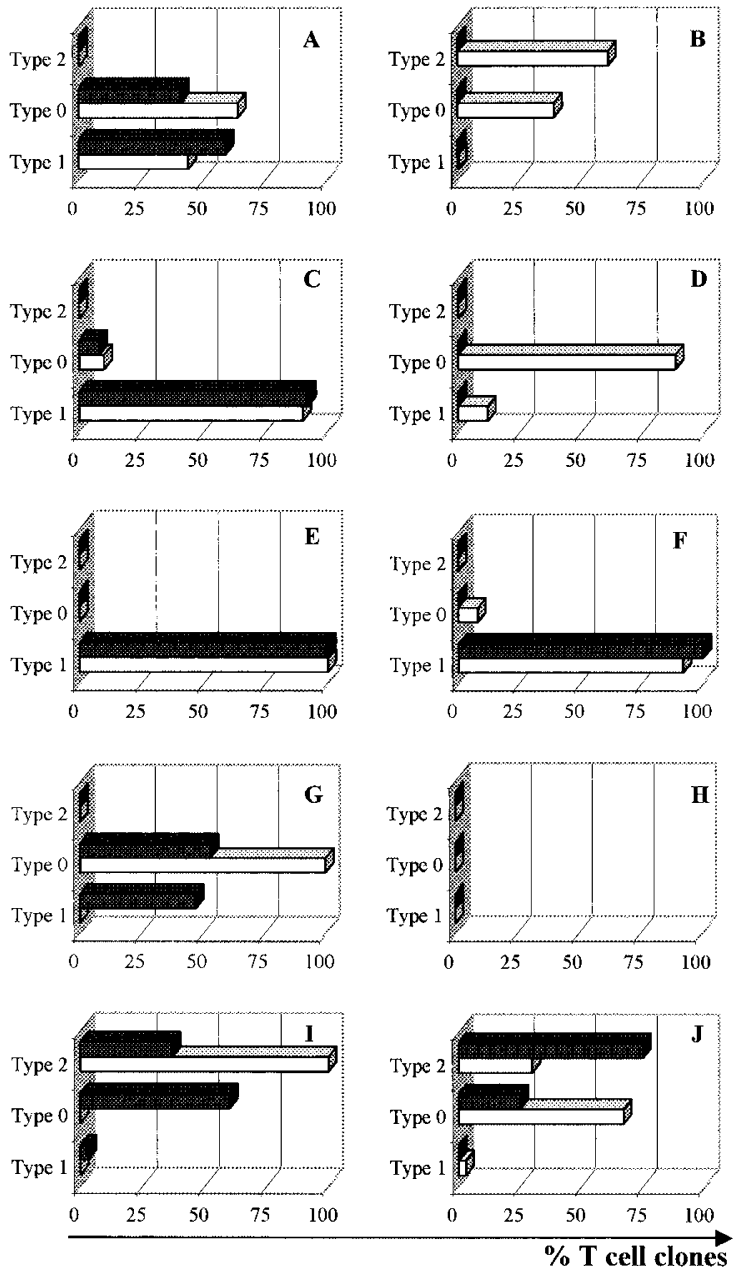

Figure 3 .

Distribution of $\mathrm{CD} 4^{+} \mathrm{TCC}$ (white bars) and $\mathrm{CD}^{+}{ }^{+} \mathrm{TCC}$ (black bars) with respect to their IFN- $y /$ IL-4 ratio. Note the predominance of Type-1-like TCC in the PL skin of active patients. The classification of the clones was determined based on their IFN- $\gamma /$ /L-4 ratio as previously reported (Verhagen et al, 1997). Clones with the ratio $\geq 20$ were considered to be Type- 1 . Clones with the ratio $\leq 0.4$ were considered to be Type-2. The remaining clones were qualified as Type-0. A and B, Patient 1; C and D, Patient 2; E and F, Patient 3; G and H, Patient 4; I and J, Patient 5. In H, No NL TCC were generated for Patient 4.

not statistically significant. In summary, we could conclude that polarization of T-cell cytokine profiles within PL skin and NL skin involved in microdepigmentation as opposed to nondepigmented skin or stabilized depigmented lesion, results from up-regulation of Type- 1 cytokine IFN- $\gamma$ and TNF- $\alpha$ and is accompanied by the down-regulation of Type-2 cytokines, IL-4, IL-5, and IL-13.

\section{CD8 + TCL- and TCC-Mediated Cytotoxicity Against Autologous Melanocytes}

Possible presence of CD8-positive cytotoxic T cell clones (CTL) in TCL and in the groups of pooled 20 TCC from Patient 1 were tested in 6 -hour ${ }^{51} \mathrm{Cr}$ release assay to investigate their lytic activities against autologous melanocytes pretreated with $500 \mathrm{U} / \mathrm{ml}$ of IFN- $\gamma$

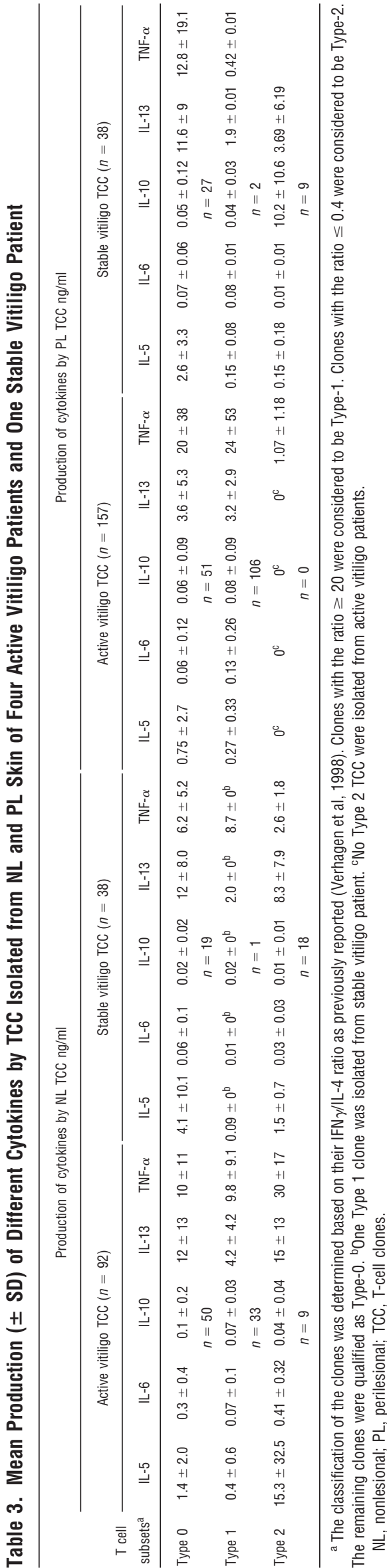


to up-regulate MHC I expression. Representative examples of these cytotoxicity assays are illustrated in Figure 4, A and B. It can be seen that percentage of lysis by TCL and pooled TCC increases proportionally with higher E:T ratios. Significant degree of lysis was detected in the pool of several TCC (Fig. 4B) and four individual TCC from that pool (Fig. 4C). Similarly, two CD8-positive TCC demonstrating the lysis of autologous melanocytes were isolated from $\mathrm{PL}$ skin of Patient 3. Uninvolved $\mathrm{CD}^{+}$TCC generated from Patient 3 did not lyse autologous melanocytes (data not shown), although these TCC appeared to preferentially secrete IFN- $\gamma$ in response to TCR triggering, whereas at least two TCC of PL skin from the same patient showed cytotoxic activity against the autologous melanocytes targets.

During the series of experiments we observed that CD8-positive TCC were difficult to propagate in culture, which limited elaborate studies on these clones. Nevertheless, to ensure that CTL activity was specific and $\mathrm{MHC}$-class I restricted, we performed the cytotoxicity assays using two representative and relatively more stable CD8 TCC, numbers 12 and 13 from PL skin of Patient 3, against autologous melanocytes in the presence and absence of anti-MHC I blocking $\mathrm{mAb}$, as well as against unrelated NK cell, target cell line K562. The results suggest strongly that cytotoxic effects are melanocyte-specific and $\mathrm{MCH}$-restricted (Fig. 4D).

\section{Tetramer Analysis}

Both peripheral blood monocyte cells (PBMCs) and skin-infiltrating T-cell samples were cultured in an identical way to properly compare the frequencies of antigen-specific T cells. In addition, PBMCs from all patients were stained with tetramer without previous stimulation. Interestingly, peripheral blood CD8 T cells did not stain with the tetramer used in this study, with or without stimulation step (data not shown). Among T-cell lines isolated from the skin, only T-cell lines derived from Patients 3 and 5 revealed high frequencies of Mart-1-specific T cells (Fig. 5). Strikingly, as much as $2.2 \%$ of CD8 T cells derived from the PL skin of Patient 3 were staining with Mart-1 tetramer. Lower, but significant, percentage $(0.66 \%)$ was detected in the CD8 population of NL TCL of Patient 5. Because the $\mathrm{T}$-cell lines were expanded in antigen-independent manner, it is conceivable to believe that percentages detected by us truly reflect local enrichment of Mart1-specific T cells. Interestingly, also NL skin-derived T-cell lines contained lower but significant numbers of Mart-1-specific T cells. Both of these TCL were derived from skin that was macroscopically described as "nonlesional" but proved to contain foci of microscopic depigmentation when analyzed by immunohistochemistry.

\section{Discussion}

This article is the first report on the in vitro characterization of infiltrating $\mathrm{T}$ cells in human vitiligo, which clearly demonstrates that immunopolarization of these $\mathrm{T}$ cells toward Type-1-like cytokine profile is associated with melanocyte destruction. We have isolated and characterized infiltrating $T$ cells from skin biopsies of vitiligo patients with active or stable disease. In situ immunohistochemical analysis of skin biopsies confirmed the consistent presence of T-cell infiltrates composed predominantly of $\mathrm{CD}^{+} \mathrm{T}$ cells in the $\mathrm{PL}$ skin, in apposition to residual melanocytes, as reported earlier (Le Poole et al, 1996; van den Wijngaard et al, 2000). In contrast, T cells present in the normal skin of healthy donors are usually characterized by equal distribution of CD4 and CD8 subsets, and 90\% are found in the dermal, perivascular areas of the dermis (Bos et al, 1987). The predominance of CD8 ${ }^{+} \mathrm{T}$ cells over $\mathrm{CD}^{+}{ }^{+} \mathrm{T}$ cells as well as their localization near melanocytes may represent an effector phase of the antimelanocyte response, as it has been described for the Smyth chicken model of vitiligo (Shresta et al, 1997). In other human autoimmune diseases high frequencies of $\mathrm{CD}^{+} \mathrm{T}$ cells have been described in the cellular infiltrate within the affected organs, eg, the pancreas in insulin-dependent diabetes mellitus or the thyroid gland in Hashimoto's thyroiditis (Del Prete et al, 1986; Itoh et al, 1993). We also have observed T-cell infiltrates in the dermoepidermal junction of macroscopically normal pigmented skin in three of five patients, displaying microscopic disappearance of melanocytes. This microdepigmentation, which to the best of our knowledge is a novel observation, seems to occur in the presence of higher percentages of $\mathrm{CD}^{+} \mathrm{T}$ cells in the infiltrates compared with these found in PL skin. When analyzing the skin biopsies from healthy individuals and NL skin biopsies from patients with other inflammatory skin diseases, such microdepigmentation was never observed (Le Poole et al, 1996; van den Wijngaard et al, 2000). The appearance of microdepigmentation may represent an early stage in the development of macroscopically overt vitiligo lesions. Alternatively, microdepigmentation may constitute a subclinical, but stable form of vitiligo, as one can speculate in the case of NL skin of Patient 5 (Fig. 1J). This patient, in contrast to other patients with microdepigmentation, did not present with any new lesions during a yearly follow-up examination.

Because T-cell infiltrates in vitiligo are usually paucicellular, we were not able to analyze the initial cell populations obtained from each skin biopsy because of limiting cell numbers. We chose to generate TCL by mitogenic expansion to avoid deletion of effector-type cytotoxic $T$ cells that could potentially be present in the affected skin. In most cases similar or same percentage distributions of T-cell phenotypes in generated TCL compared with that in situ were observed (Table 2).

T-cell lines generated after one round of stimulation in vitro were subsequently analyzed for antigen specificity and cytokine production. Remaining cells were used to generate T-cell clones. Our cloning procedure did not alter the distribution of T-cell subsets in vitro in most cases, which allowed us to directly compare the cytokine production profiles between single cells de- 

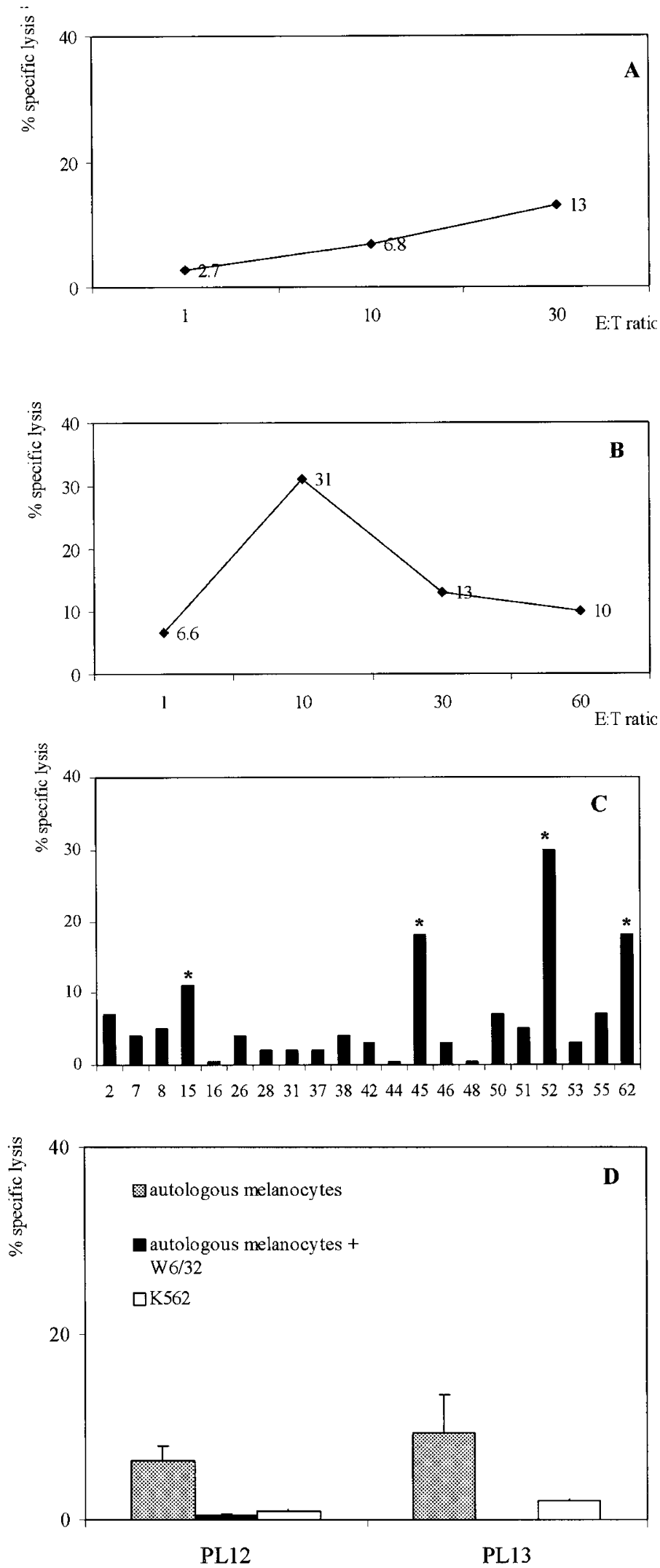

Figure 4.

A, Lysis of autologous melanocytes by T-cell lines (TCL) derived from PL skin of Patient 1. B, High degree of lysis was detected in the pool containing 20 TCC derived from PL TCL of Patient 1. C, Individual testing of all clones from the pool revealed highest lytic levels by clones 15, 45, 52, and 62 (asterisks). D, Lysis of autologous melanocytes and K562 cells by 2 CD8 $^{+}$TCC derived from PL skin of Patient 3. Effector:target ratio (T cells versus melanocytes) was 10:1 when not indicated otherwise. 
Patient 3 - NL T cell line
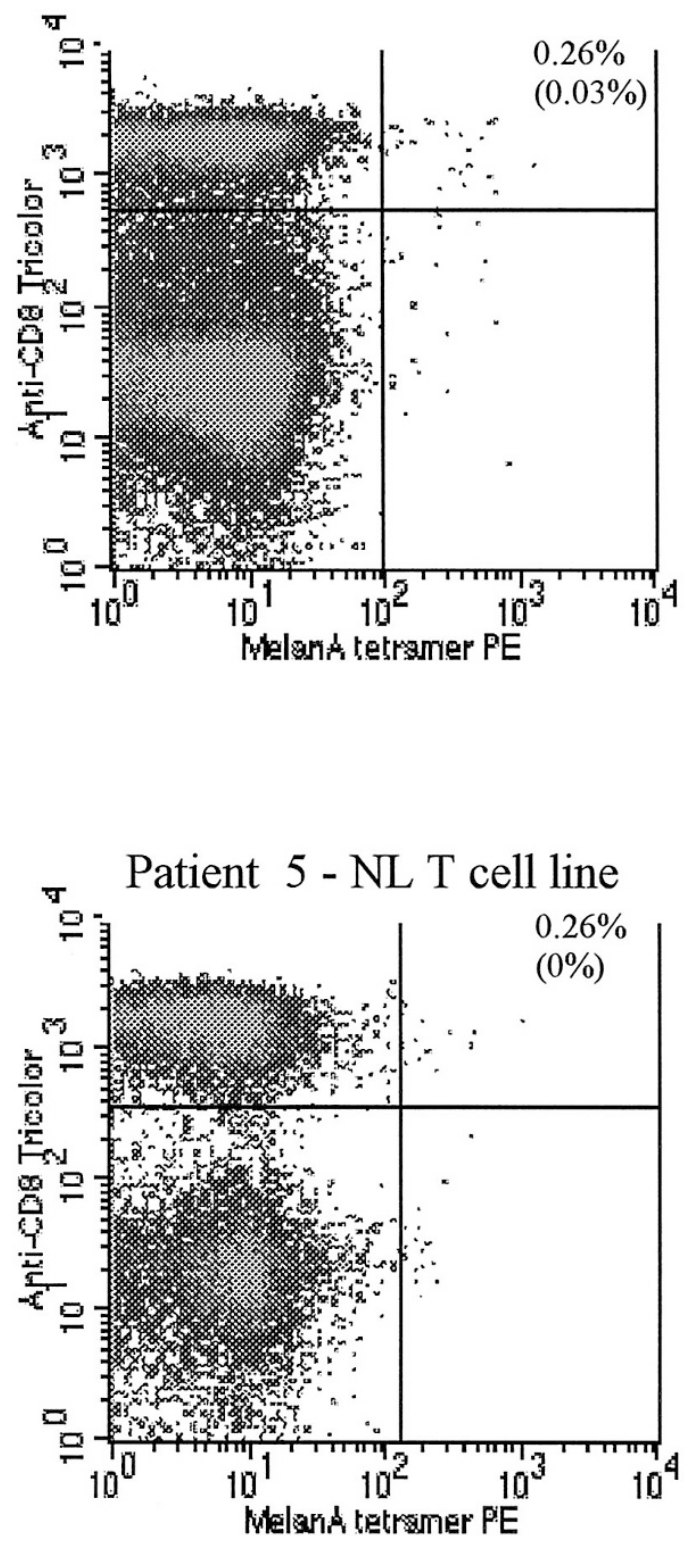

Patient 3 -PL T cell line
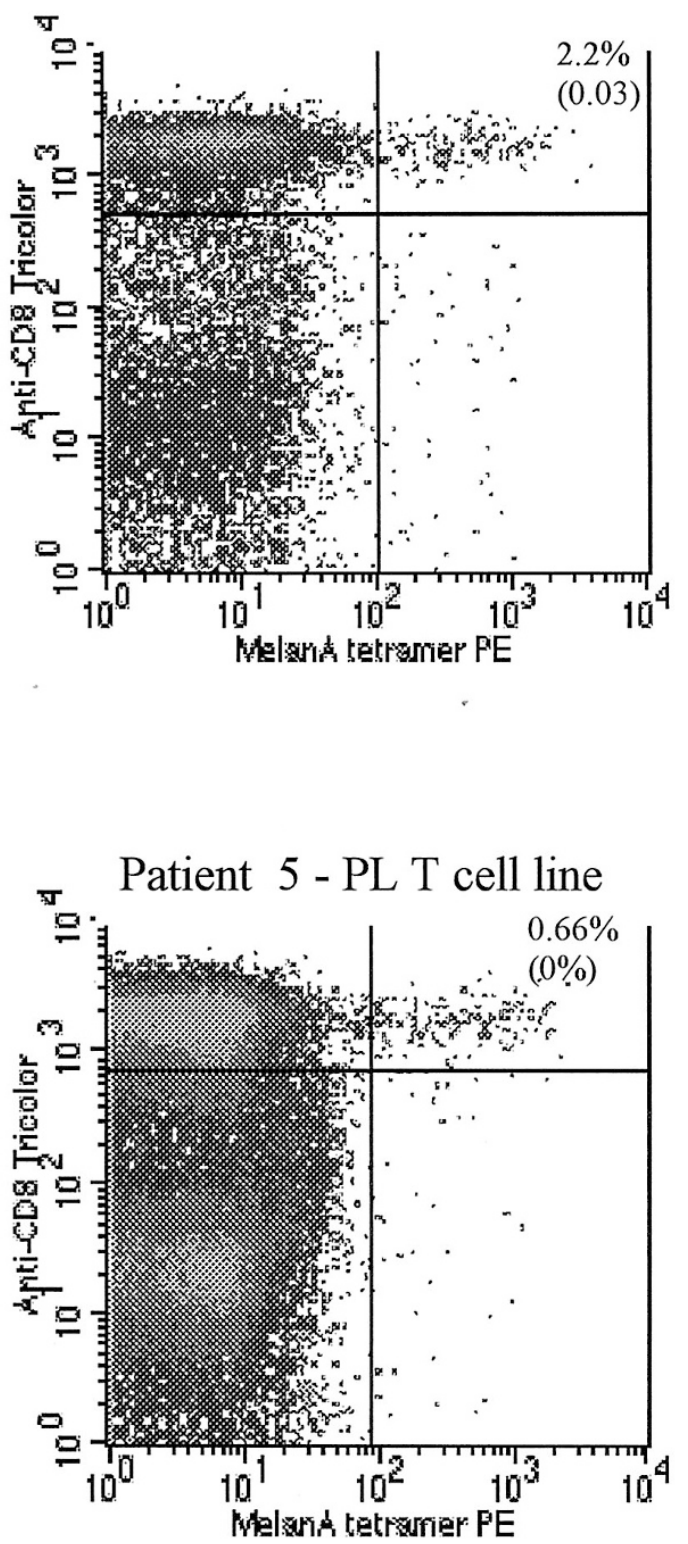

Figure 5.

Presence of Mart-1-specific CD8 ${ }^{+}$T cells in the TCL of two vitiligo patients. Numbers refer to percentages of CD8 ${ }^{+}$cells that stained positive with Mart- 1 tetramer Numbers in parentheses indicate the percentage of Mart-1-positive cells within the PBMCs.

rived from $\mathrm{PL}$ and $\mathrm{NL}$ skin. Strikingly, high percentages of both $\mathrm{CD}^{+}$and $\mathrm{CD}^{+}{ }^{+}$TCC producing predominantly IFN- $\gamma$ were recovered from the PL skin of all four patients with active vitiligo. In contrast, in the case of Patient 5, who is clinically stable, PL T cells did not show this predominant skewing toward a Type-1like cytokine profile. In situ analysis revealed different distribution of T-cell infiltrates in this patient, ie, deep in the dermis instead of being in close contact with disappearing melanocytes around dermoepidermal junction (Fig. 1I). Because the lesional, melanocytefree area was well demarcated, one might conclude that this particular vitiliginous lesion might have already undergone spontaneous stabilization. This hypothesis is in agreement with the clinical assessment of this patient at the time of biopsy, as well as, at his yearly clinical follow-up evaluation. This patient did not develop any new lesions and reported some spontaneous repigmentation observed in several areas of the body.

In the NL skin of Patients 2 and 3, the intensity of microdepigmentation process was clearly correlated with the percentages of recovered Type-1-like TCC. A low percentage of Type-1 CD4 ${ }^{+}$clones (14\%) was isolated from NL skin of Patient 2, whose NL skin biopsy revealed localized microdepigmentation spot. Interestingly, almost $100 \%$ of $\mathrm{CD}^{+}$and $\mathrm{CD}^{+}$TCC isolated from NL skin of Patient 3 belonged to Type-1. In contrast, TCC isolated from NL skin of Patient 5, which actually did show a prominent microdepigmen- 
tation, belonged predominantly to $\mathrm{CD}^{+}$Type-2-like subset, reflecting possibly the lesion in its stabilized phase.

Our data suggest that Type-1-like T cells might be responsible for the destruction of melanocytes in vitiligo, not only via direct cytotoxic effects, but also by modulation of the local cytokine microenvironment. Indeed, as it has been reported in a transgenic mice model, high local concentrations of IFN- $\gamma$ within the epidermis may lead to the hypopigmentation of hair follicles (Carroll et al, 1997). The isolation of such strongly polarized T-cell subsets from the actual site of the immune process suggests that the local microenvironment directly influences the Type-1 cytokine bias in these $\mathrm{T}$ cells, as was reported for $\mathrm{CD} 4^{+} \mathrm{T}$ cells in EAE, a murine model of multiple sclerosis (Krakowski and Owens, 1997).

Analysis of several cytokines broadly used in the classification of functional T-cell subsets (Carter and Dutton, 1996; Mosmann and Sad, 1996) allowed us to better characterize the vitiligo-derived TCC. Clearly, depigmentation detected macroscopically, as well as microdepigmentation, was accompanied by strong polarization of cytokine production by infiltrating TCC, ie, up-regulation of IFN- $\gamma$ and down-regulation of IL-4, IL-5, and IL-13, compared with TCC derived from noninvolved skin free of depigmentation or NL and $\mathrm{PL}$ TCC of a stable vitiligo patient. Strikingly, higher levels of TNF- $\alpha$ were detected in Type 0,1 , and even 2-like TCC isolated from active vitiligo patients then that of a stable patient (Table 3). High production of TNF- $\alpha$ by autoreactive $T$ cells has been reported to be detrimental in multiple sclerosis and rheumatoid arthritis (Kagi et al, 1999; Selmaj and Raine, 1988), and therapies designed to neutralize or antagonize TNF- $\alpha$ have proven clinically effective. The synergistic in situ action of T-cell-derived TNF- $\alpha$ and IFN- $\gamma$ may be responsible for the reported up-regulation of $\mathrm{MHC}$ II as well as ICAM-1 molecules on perilesionally located melanocytes in vitiligo (al Badri et al, 1993). Because melanocytes can process and present protein-derived antigenic peptides to antigen-specific CD4 ${ }^{+} \mathrm{T}$ cells after pretreatment with IFN- $\gamma$ (Le Poole, 1993a), high local concentration of IFN- $\gamma$ and TNF- $\alpha$ may contribute to heightened immune surveillance of melanocytes. The dominant role for IL-13 in the process of melanocytes disappearance cannot be concluded, although quite remarkably almost all of generated $\mathrm{CD}^{+}{ }^{+}$and $\mathrm{CD}^{+}{ }^{+} \mathrm{TCC}$ produced varied amounts of this cytokine. Although the highest levels were detected in Type-2 TCC isolated from NL skin of Patient 1 (Table 3), Type-0 and, most interestingly, Type-1 $\mathrm{CD}^{+}$and $\mathrm{CD}^{+}{ }^{+} \mathrm{TCC}$ represented significant source of this cytokine. This is in agreement with a previous report (Verhagen et al, 1997); however, the role of IL-13 production and its influence on melanocytes remains to be established.

It has recently been reported that the PBMCs from patients with vitiligo contain much higher frequencies of antimelanocyte CTLs than those of healthy controls (Ogg et al, 1998), and that passive transfer of melanocyte-specific $T$ cells can lead to accumulation of these cells not only in a melanoma lesion but also in normal skin, leading to the depigmentation (Yee et al, 2000), but presence of CTLs in the skin mediating autoimmune destruction of melanocytes was never reported. In this study, several CD8 ${ }^{+}$TCC generated from PL skin were able to lyse autologous melanocytes in vitro in MHC-restricted manner (Fig. 4D). Specific lysis was arguably low, which is in agreement with similar data obtained in multiple-sclerosis patients when allogeneic HLA-matched oligodendrocytes were used as target cells for in vitro-generated, peptide-specific CTL (Jurewicz et al, 1998). Low degree of melanocyte-specific lysis could be caused by low avidity of self-reactive T cells, as well as heterogeneity of cultured autologous melanocytes in terms of the expression of self-antigens and $\mathrm{MHC}$ class I. Blocking by anti-MHC I antibody (Fig. 4D) supports the MHC-restricted specificity of CD8-positive TCC. Moreover, we also observed lysis of autologous melanocytes using the PL TCL as effector cells from which the clones shown in Figure $4 \mathrm{C}$ were obtained. Sixteen remaining clones generated from the same TCL did not show any degree of melanocyte lysis in the same set of experiments. This, together with the fact that autologous melanocytes were used in all assays, suggests that demonstrated CTL activity of these clones is specific and MHC-restricted, and not NK-like or MLR-like response. Our data, together with other reports (Jurewicz et al, 1998; Sugihara et al, 1995), underlines the importance of $\mathrm{CD}^{+} \mathrm{T}$-cellmediated effector function in human autoimmune diseases.

TCL, from which the TCC were generated, also were tested for antigen specificity using Mart-1/Melan A tetramer, a reagent that allows for detection of antigen-specific $T$ cells by using a simple flowcytometry analysis (Ogg et al, 1998). In two of five cases skin-derived T cells contained high percentages of melanocyte-specific CD8 T cells. Because we did not culture the lines with any melanocyte-specific antigen, we can conclude that the high frequency of Mart-1-specific CD8 T cells in the perilesional as well as nonlesional skin of these patients reflected an expansion of these $T$ cells in situ or enhanced migration of melanocyte-specific $T$ cells from the neighboring lymph nodes. Not surprisingly, Mart-1-specific T cells also were present in the nonlesional skin of these two patients; in both cases we observed a microdepigmentation phenomenon, affecting that skin. Strikingly, the highest percentages of Mart-1-specific $T$ cells were detected in two patients in two totally different vitiligo stages: one in active, the other in a stable phase of the disease. It could be speculated that differences between cytokine profiles of their skin-infiltrating T-cell populations could account for that discrepancy. Both nonlesional and perilesional T-cell lines as well as clones of Patient 3 in active stage of the disease were characterized by a strong polarization of cytokine profile toward Type-1-like, with high production of IFN- $\gamma$ and TNF- $\alpha$, known to support cellular immune responses. T-cell lines and clones of Patient 5 produced cytokines that allow 
classifying them as Type-0 and Type-2. It has been shown in human multiple sclerosis that strong polarization of cytokine production toward Type-1 correlated with progressive stage of the disease while stabilization of the disease by treatment was leading to increased frequencies of Th2 cells (Comabella et al, 1998). Although this study is far too limited to allow drawing strong conclusions, it is likely that similar phenomenon occurs in autoimmune vitiligo.

Second, we were able to confirm previously described dominant role of anti-Mart-1 CD8 responses in autoimmune vitiligo (Lang et al, 2001; Ogg et al, 1998) by showing for the first time the presence of melanocytespecific $\mathrm{T}$ cells in the skin undergoing depigmentation. However, we failed to observe similarly high frequencies of Mart-1-specific CD8 T cells in the periphery (Ogg et al, 1998; Palermo et al, 2001). Most interestingly, peripheral blood of Patients 3 and 5 did not contain significant numbers of Mart-1-specific CD8 T cells, whereas their skin-infiltrating $\mathrm{T}$-cell population was highly enriched for these cells. This result could reflect the recirculation of antigen-specific $T$ cells into the peripheral site of antigen expression and further underlines the necessity of parallel screening of peripheral as well as local T-cell repertoire. As reported in several tumor vaccination studies, increased frequencies of tumor-specific T cells detected in the peripheral blood did not necessary correlate with tumor regression (Lee et al, 1999), possibly because of the lack of their recirculation to the tumor site.

This is the first, to our knowledge, demonstration of the presence of melanocyte-specific $\mathrm{T}$ cells in the depigmented skin of autoimmune vitiligo patients. Studies published so far described presence of such cells in peripheral blood, either directly ex vivo or after in vitro culture (Lang et al, 2001; Ogg et al, 1998; Palermo et al, 2001), with vitiligo patients having higher percentages of these cells in their blood than healthy donors. Moreover, it suggests that the polarization of both CD4 and CD8 T-cell subsets present locally in the skin of vitiligo patients toward Type-1 correlates with the depigmentation process observed macro- and microscopically.

\section{Materials and Methods}

\section{Patients}

Five individuals with vitiligo were recruited with their consents through the Dutch Institute for Pigment Disorders (SNIP) in Amsterdam and under the responsibility of one of us (WW). Patients' details are described in Table 1. No patients exhibited any other autoimmune conditions and were not treated with immunosuppressive therapy before surgical excision of biopsies. HLA genotyping revealed that all five patients were HLA-A2.01-positive.

\section{Skin Biopsies}

Six-millimeter biopsies were resected from the perilesional area of vitiliginous skin, and from normally pigmented skin of each patient. PL skin biopsies were taken spanning the border between depigmented and pigmented skin. NL skin biopsies were taken from sites deemed macroscopically free from depigmentation and distal to perilesional sites, usually on a different limb. Fresh biopsies were cut in half, with one-half snap-frozen in liquid nitrogen for immunohistochemical analysis. The other half of the biopsy was used for the isolation of skin-infiltrating $T$ cells.

\section{Generation of Autologous Melanocytic Lines}

Autologous split skin was taken from Patients 1 and 3 with the use of a dermatome (Aeskulap, Tuttlingen, Germany). Isolation of epidermal cell suspension (ECS) was performed as previously described (Le Poole et al, 1993a). ECS was then seeded in the $75-\mathrm{mm}^{2}$ tissue culture flask (Falcon, Costar, Cambridge, United Kingdom). The culture medium consisted of HAM's F-10 (Flow Laboratories, Scotland) supplemented with $10 \mu \mathrm{g} / \mathrm{ml}$ 12-0-tetradecanoylphorbol 13-acetate (PMA) (Sigma Chemicals, St. Louis, Missouri), $0.1 \mathrm{~nm}$ isobutyl-methyl-1-xanthine (IBMX) (Sigma), $1 \%$ Ultroser G (Sigma), 2 mm glutamine (Gibco, Rijswijk, The Netherlands), and $100 \mathrm{IU} / \mathrm{ml}$ penicillin $/ 100 \mu \mathrm{g} / \mathrm{ml}$ streptomycin (Gibco). Overgrowth of fibroblasts and keratinocytes was prevented by addition of geneticine 1/100 (G418) (Sigma), when necessary. Confluent melanocytes were harvested by trypsinization as described before (Le Poole et al, 1993a) and used for experiments.

\section{Generation of Skin-Derived T-Cell Lines and T-Cell Clones}

TCL and TCC were generated as previously described (Verhagen et al, 1997). Fresh biopsies were incubated in a well of a 24-well culture plate (Costar, Cambridge, Massachusetts) that was precoated with $10 \mu \mathrm{g} /$ well of fibronectin (Sigma) to facilitate the spontaneous migration of $\mathrm{T}$ cells from the biopsy into the IMDM medium (Iscove's Modified Dulbecco's Medium, Life Technologies, Paisley, United Kingdom) supplemented with 10\% of normal human serum (NHS, Biowhittaker, Walkersville, Maryland), 1 mm glutamine (Life Technologies), 100 $\mathrm{IU} / \mathrm{ml}$ of penicillin, and $100 \mu \mathrm{g} / \mathrm{ml}$ streptomycin (Life Technologies). After 5 days, extravasated skin T cells were transferred to an uncoated 24-well plate and expanded by mitogenic stimulation with $0.05 \%$ PHA (Difco, Detroit, Michigan) in the presence of irradiated (3000 rad) allogeneic feeder cells consisting of PBMCs $\left(10^{6}\right.$ cells/ well) from two unrelated donors, EBV transformed B cells (JY, $1-2 \times 10^{5}$ per well) and $10 \mathrm{U} / \mathrm{ml}$ of recombinant hulL-2 (Eurocetus, Amsterdam, The Netherlands). After 10 days TCL were phenotyped and tested for cytokine production. On Day 14 after initial stimulation TCL were harvested and subjected to the cloning procedure, as described previously (Wierenga et al, 1991). After an additional 14 days, generated TCC were expanded further using an allogeneic feeder mixture, as described above. Ten days later, TCC were harvested, phenotyped, and analyzed for cytokine production.

\section{Phenotyping of T Cells}

Immunohistochemical in situ analysis of T-cell infiltrates was performed using double stainings and the reagents 
as previously described (van den Wijngaard et al, 2000; Verhagen et al, 1997). CD3/CD8 double staining was performed to estimate the ratio between $\mathrm{CD}^{+}$and $\mathrm{CD}^{+}{ }^{+} \mathrm{T}$ cells, with the absolute number of $\mathrm{CD} 4^{+} \mathrm{T}$ cells calculated as the total number of $\mathrm{CD}^{+} \mathrm{T}$ cells minus the total number of CD3/CD8 double-positive $T$ cells. To visualize interaction between infiltrating $T$ cells and melanocytes, CD3/NKI-beteb and CD8/NKI-beteb double stainings were performed. For flow cytometry (FACS) analysis of cultured T-cell lines and clones, FITC-CD3 (Becton Dickinson, Brussels, Belgium), FITC-CD4 (Becton Dickinson), FITC-CD8 (DAKO, Copenhagen, Denmark), FITC-TCR $\alpha \beta$ (Becton Dickinson), and PE-TCR $\gamma \delta$ (Becton Dickinson) monoclonal antibodies were used.

\section{Cytokine Production by TCL and TCC}

On the Day 10 after initial stimulation, T cells from TCL and TCC were stimulated mitogenically by incubating $10^{5}$ cells in a flat-bottom, 96-well plate with immobilized anti-CD3 mAb (OKT3, $1 \mu \mathrm{g} / \mathrm{ml}$, American Type Culture Collection, Rockville, Maryland) and soluble PMA (1 ng/ml, Sigma) in a total volume of $200 \mu \mathrm{l} /$ well in flat-bottom, 96-well plate. After 24 hours, $150 \mu$ l of cell-free supernatant was collected and stored at $-80^{\circ} \mathrm{C}$ until tested. Proliferation in the remaining cultures was confirmed in $16-\mathrm{h}\left[{ }^{3} \mathrm{H}\right]$ thymidine $(0.3$ $\mu \mathrm{Ci} /$ well; Amersham, Buckinghamshire, United Kingdom) incorporation assays. The concentrations of secreted cytokines (namely IFN- $\gamma$, IL-4, IL-5, IL-6, $\mathrm{IL}-10, \mathrm{IL}-13$, and TNF- $\alpha$ ) in the culture supernatants were measured with specific sandwich ELISAs as described previously (Verhagen et al, 1997).

\section{Cytotoxicity Assays}

Autologous target $(T)$ melanocytes were preincubated for 48 hours with $500 \mathrm{U} / \mathrm{ml}$ of IFN- $\gamma$ (TNO, Rijswijk, The Netherlands) for 48 hours, trypsinized, counted, and labeled for 1 hour with ${ }^{51} \mathrm{Cr}\left(2 \mu \mathrm{Ci} / 10^{4}\right.$ cells, Amersham). After thorough washing with $\mathrm{RPMI} / 5 \% \mathrm{FCS}$ to remove free ${ }^{51} \mathrm{Cr}, 2 \times 10^{4}$ or $10^{4}$ melanocytes were co-cultured (in triplicate determinations) with isolated autologous effector (E) T cells at various E:T ratios for 6 hours in a fully humidified $5 \% \mathrm{CO}_{2}$-air mixture at $37^{\circ} \mathrm{C}$. Cell-free supernatant was collected from each well and the ${ }^{51} \mathrm{Cr}$ release from the target melanocytes was determined using gamma counter. The percentage of specific lysis was calculated according to the formula: \% specific lysis $=\left[\right.$ (experimental ${ }^{51} \mathrm{Cr}$ release - spontaneous ${ }^{51} \mathrm{Cr}$ release): (maximal ${ }^{51} \mathrm{Cr}$ release - spontaneous ${ }^{51} \mathrm{Cr}$ release) $\times 100$. Spontaneous release (melanocytes cultured with medium alone) never reached more than $20 \%$ of the maximal release melanocytes exposed to $1 \%$ Triton X-100. Confirmation of the class I-restricted nature of cytotoxicity was determined by pretreating of radiolabeled melanocyte targets with the mAb W6/32 (DAKO) before adding to assay wells. The antibody was dialyzed overnight against PBS $\mathrm{pH} 7.4$ to remove the sodium azide before use. Initially, PL cell lines were tested in cytotoxicity assay, followed by cloning procedure and testing of the pooled clones. This was performed to confirm the lysis before laboriously testing all of the clones, which was strongly limited by the number of autologous targets available. Once the lysis was confirmed in the pool, we then tested all clones from the positive pool.

\section{Tetramer Analysis}

PBMCs and T-cell lines derived from NL and PL skin of all five patients were analyzed by tetramer staining. We used tetramer-containing peptide Mart-1 (26-35) ELAGIGILTV. Briefly, purified HLA heavy chain and $\beta 2$ microglobulin were synthesized using a prokaryotic expression system (pET; Novagen, Milwaukee, Wisconsin). The heavy chain was modified by deletion of the transmembrane/cytosolic tail and $\mathrm{COOH}$-terminal addition of a sequence containing the BirA enzymatic biotinylation site. The $45-\mathrm{kD}$ refolded product was isolated using fast protein liquid chromatography (FPLC), biotinylated by BirA (Avidity, Denver, CO) in the presence of biotin (Sigma), ATP (Sigma) and $\mathrm{Mg}^{2+}$ (Sigma). The biotinylated product was separated from free biotin by gel filtration and ion exchange using FPLC. Streptavidin-PE conjugate (Sigma) was added in a 1:4 molar ratio and the tetrameric product was concentrated to $1 \mathrm{mg} / \mathrm{ml}$. Analysis of cells for the expression of cell surface markers was performed using a FACScan (Becton Dickinson) and CellQuest software (Becton Dickinson). Frozen PBMC and T-cell lines were thawed and incubated for 24 to 48 hours in RPMI 1640 supplemented with 10\% FCS to allow recovery of cell viability. Cells, $10^{6}$, were centrifuged at $300 \mathrm{~g}$ for 5 minutes and resuspended in 50- $\mu$ l cold PBS. After two washes with PBS, anti-rat IgM-FITC (PharMingen) was added and the cells left for a further incubation on ice for 20 minutes. After two washes with PBS, the tetramer and anti-CD8-Tricolor (Caltag Laboratories, Burlingame, California) were added and incubated for another 20 minutes. The samples were washed two more times with PBS before formaldehyde fixation. Triple-color analysis was performed with tetramer-PE and anti-CD8-tricolor. As a negative control for the tetramer we used irrelevant $A^{*} 0201$ tetramer (SLYNTVATL p17Gag 77-85), which allowed to set up a negative population gates. Both PBMCs and T-cell lines derived from skin were stained with tetramer after one round of antigen-nonspecific expansion in vitro to ensure comparability of the results. PBMCs also were stained directly ex vivo.

\section{Acknowledgements}

The authors thank Dr. Eddy Wierenga for critically reading the manuscript and helpful discussion, and Dr. Frans Claas for HLA-typing of our samples.

\section{References}

al Badri AM, Foulis AK, Todd PM, Gariouch JJ, Gudgeon JE, Stewart DG, Gracie JA, and Goudie RB (1993). Abnormal expression of MHC class II and ICAM-1 by melanocytes in vitiligo. J Pathol 169:203-206. 
Bos JD, Zonneveld I, Das PK, Krieg SR, van der Loos CM, and Kapsenberg ML (1987). The skin immune system (SIS): Distribution and immunophenotype of lymphocyte subpopulations in normal human skin. J Invest Dermatol 88:569-573.

Carroll JM, Crompton T, Seery JP, and Watt FM (1997). Transgenic mice expressing IFN gamma in the epidermis have eczema, hair hypopigmentation, and hair loss. J Invest Dermatol 108:412-422.

Carter LL, and Dutton RW (1996). Type 1 and type 2: A fundamental dichotomy for all T-cell subsets. Curr Opin Immunol 8:336-342.

Comabella M, Balashov K, Issazadeh S, Smith D, Weiner HL, and Khoury SJ (1998). Elevated interleukin-12 in progressive multiple sclerosis correlates with disease activity and is normalized by pulse cyclophosphamide therapy. J Clin Invest 102: 671-678.

Del Prete GF, Vercelli D, Tiri A, Maggi E, Mariotti S, Pinchera A, Ricci M, and Romagnani S (1986). In vivo activated cytotoxic $T$ cells in the thyroid infiltrate of patients with Hashimoto's thyroiditis. Clin Exp Immunol 65:140-147.

Harning R, Cui J, and Bystryn JC (1991). Relation between the incidence and level of pigment cell antibodies and disease activity in vitiligo. J Invest Dermatol 97:10781080.

Itoh N, Hanafusa T, Miyazaki A, Miyagawa J, Yamagata K, Yamamoto K, Waguri M, Imagawa A, Tamura S, and Inada M (1993). Mononuclear cell infiltration and its relation to the expression of major histocompatibility complex antigens and adhesion molecules in pancreas biopsy specimens from newly diagnosed insulin-dependent diabetes mellitus patients. J Clin Invest 92:2313-2322.

Jurewicz A, Biddison WE, and Antel JP (1998). MHC class I-restricted lysis of human oligodendrocytes by myelin basic protein peptide-specific CD8 T lymphocytes. J Immunol 160:3056-3059.

Kagi D, Ho A, Odermatt B, Zakarian A, Ohashi PS, and Mak TW (1999). TNF receptor 1-dependent beta cell toxicity as an effector pathway in autoimmune diabetes. J Immunol 162: 4598-4605.

Kemp EH, Waterman EA, Hawes BE, O‘Neill K, Gottumukkala RVSRK, Gawkrodger DJ, Weetman AP, and Watson PF (2002). The melanin-concentrating hormone receptor 1 , a novel target of autoantibody responses in vitiligo. $\mathrm{J}$ Clin Invest 109:923-930.

Krakowski ML and Owens T (1997). The central nervous system environment controls effector $\mathrm{CD}^{+} \mathrm{T}$ cell cytokine profile in experimental allergic encephalomyelitis. Eur J Immunol 27:2840-2847.

Lang KS, Caroli CC, Muhm A, Wernet D, Moris A, Schittek B, Knauss-Scherwitz E, Stefanovic S, Rammensee HG, and Garbe C (2001). HLA-A2 restricted, melanocyte-specific $\mathrm{CD}^{+} \mathrm{T}$ lymphocytes detected in vitiligo patients are related to disease activity and are predominantly directed against MelanA/Mart1. J Invest Dermatol 116:891-897.

Lee $\mathrm{KH}$, Wang E, Nielsen MB, Wunderlich J, Migueles S, Connors M, Steinberg SM, Rosenberg SA, and Marincola FM (1999). Increased vaccine-specific T cell frequency after peptide-based vaccination correlates with increased susceptibility to in vitro stimulation but does not lead to tumor regression. J Immunol 163:6292-6300.
Le Poole IC, Mutis T, van den Wijngaard RM, Westerhof W, Ottenhoff T, de Vries RR, and Das PK (1993a). A novel, antigen-presenting function of melanocytes and its possible relationship to hypopigmentary disorders. J Immunol 151: 7284-7292.

Le Poole IC, van den Wijngaard RM, Westerhof W, and Das PK (1996). Presence of T cells and macrophages in inflammatory vitiligo skin parallels melanocyte disappearance. Am J Pathol 148:1219-1228.

Le Poole IC, van den Wijngaard RM, Westerhof W, Dutrieux RP, and Das PK (1993b). Presence or absence of melanocytes in vitiligo lesions: An immunohistochemical investigation. J Invest Dermatol 100:816-822.

Liblau RS, Singer SM, and McDevitt HO (1995). Th1 and Th2 $\mathrm{CD}^{+} \mathrm{T}$ cells in the pathogenesis of organ specific autoimmune diseases. Immunol Today 16:34-38.

Mosmann TR and Sad S (1996). The expanding universe of T cell subsets: Th1, Th2 and more. Immunol Today 17:138-146.

Ogg GS, Rod Dunbar P, Romero P, Chen JL, and Cerundolo $\checkmark$ (1998). High frequency of skin-homing melanocytesspecific cytotoxic $T$ lymphocytes in autoimmune vitiligo. $J$ Exp Med 188:1203-1208.

Palermo B, Campanelli R, Garbelli S, Manovani S, Lantelme E, Brazzelli V, Ardigo M, Borroni G, Martinetti M, Badulli C, Necker A, and Giachino C (2001). Specific cytotoxic T lymphocyte responses against Melan-A/Mart1, tyrosinase and gp100 in vitiligo by the use of major histocompatibility complex/peptide tetramers: The role of cellular immunity in the etiopathogenesis of vitiligo. J Invest Dermatol 117:326-332.

Selmaj K and Raine CS (1988). Tumor necrosis factor mediates myelin damage in organotypic cultures of nervous tissue. Ann NY Acad Sci 540:568-570.

Shresta S, Smyth JR Jr, and Erf GF (1997). Profiles of pulp infiltrating lymphocytes at various times throughout feather regeneration in Smyth line chickens with vitiligo. Autoimmunity 25:193-201.

Sugihara S, Fujiwara H, Niimi H, and Shearer GM (1995). Self-thyroid epithelial cell (TEC)-reactive $\mathrm{CD}^{+} \mathrm{T}$ cell lines/ clones derived from autoimmune thyroiditis lesions. They recognize self-thyroid antigens directly on TEC to exhibit $T$ helper cell 1-type lymphokine production and cytotoxicity against TEC. J Immunol 155:1619-1628.

van den Wijngaard R, Wankowicz-Kalinska A, Le Poole C, Tigges B, Westerhof W, and Das PK (2000). Local immune response in skin of generalized vitiligo patients: Destruction of melanocytes is associated with the prominent presence of CLA+ T cells at the perilesional site. Lab Invest 80:1299-1309.

Verhagen CE, Wierenga EA, Buffing AA, Chand MA, Faber WR, and Das PK (1997). Reversal reaction in borderline leprosy is associated with a polarized shift to type 1-like mycobacterium leprae $T$ cell reactivity in lesional skin: $A$ follow-up study. J Immunol 159:4474-4483.

Wierenga EA, Snoek M, Jansen HM, Bos JD, van Lier RA, and Kapsenberg ML (1991). Human atopen-specific types 1 and 2 T helper cell clones. J Immunol 147:2942-2949.

Yee C, Thompson JA, Roche P, Byrd DR, Lee PP, Piepkorn M, Kenyon K, Davis MM, Riddel SR, and Greenberg PD (2000). Melanocyte destruction after antigen-specific immunotherapy of melanoma: direct evidence of $\mathrm{T}$ cell-mediated vitiligo. J Exp Med 192:1637-1643. 